\title{
有限水深域における海洋波の非線形相互作用に 関する数值計算
}

橋本典明* - 鶴谷廣一** . 中川康之***

\section{1.はじめに}

波浪の発達・減衰を支配する重要な物理過程に非線形 相互作用がある.これは異なる周波数・伝播方向を有す る無数の成分波間でエネルギー交換を引き起こすメカニ. ズムで, 風から波へのエネルギー輸送や砕波等によるエ ネルギー散逸と同様に重要な物理過程である. 現在の波 浪予報モデルでは，いかに正確にこのメカニズムをモデ ルに導入するかが, 急務かつ最重要な課題となっている. 本研究で対象とした非線形相互作用のメカニズムは Hasselmann (1962), Herterich ら (1980) により定式化 されたものである。しかしながら，その導出過程は難解 で, 実際の計算に際しては Boltzmann 積分の特異点処理 の問題等いくつかの問題を含み, また多大の計算時間を 要するため, 現実的な連続スペクトルを対象として非線 形相互作用の計算を試みた例はこれまでにもあまり多く ない. 既往の計算例の内, Hasselmann ら (1981) は深水 域および有限水深域の波浪を対象とした計算例を報告し ている。しかしながら, それらの結果は数值的に不安定 である。一方, Masuda (1980), 小松ら（1993）は巧み な工夫を導入し，高速かつ高精度に非線形相互作用を計 算可能な方法を提案しているが, 適用が深海波に限られ ている.

非線形相互作用は波浪の発達・減衰過程に常に内在す るメカニズムであり, 他の物理過程と複合的に観測され る.このため, 実験や観測で得られたデー夕をもとにこ のメカニズムを検討しょうとしても, 直接的には検討す ることは出来ず，理論の援用が不可欠である. Masuda, 小松らの方法は深海波に適用が限られているものの, Hasselmann らの計算法よりも精度や計算時間の面で優 れており,この方法を有限水深域にも適用可能な形に拡 張できれば，有限水深域も含む合理的かつ高精度な第三 世代波浪予報モデルの開発に寄与できるものと思われ る.

本研究は, Masuda, 小松らの理論を拡張し, 深水域の

* 正会員 工博 運輸省港湾技術研究所海洋環境部水理研究室長

** 正会員 工博 運輸省港湾技術研究所海洋環境部環境評価研究室長

*** 正会員 工修 運輸省港湾技術研究所海洋環境部水理研究室
みならず有限水深域にも適用可能な計算式の定式化を行 い, 数值計算によってその妥当性を検討したものである.

\section{2. 有限水深域における非線形相互作用の定式 化}

Hasselmann（1962）により導出された成分波間の非線 形相互作用による波浪のエネルギースペクトルの時間発 展を記述する Boltzmann 積分は次式で表される.

$$
\begin{aligned}
& \frac{\partial n\left(\boldsymbol{k}_{4}\right)}{\partial t}=\int \ldots \int d \boldsymbol{k}_{1} d \boldsymbol{k}_{2} d \boldsymbol{k}_{3} G\left(\boldsymbol{k}_{1}, \boldsymbol{k}_{2}, \boldsymbol{k}_{3}, \boldsymbol{k}_{4}\right) \\
& \quad \times \delta\left(\boldsymbol{k}_{1}+\boldsymbol{k}_{2}-\boldsymbol{k}_{3}-\boldsymbol{k}_{4}\right) \delta\left(\omega_{1}+\omega_{2}-\omega_{3}-\omega_{4}\right) \\
& \quad \times\left\{n_{1} n_{2}\left(n_{3}+n_{4}\right)-n_{3} n_{4}\left(n_{1}+n_{2}\right)\right\} \cdots \cdots \cdots \cdots
\end{aligned}
$$

ここに, $n_{j} \equiv n\left(\boldsymbol{k}_{j}\right)=\phi\left(\boldsymbol{k}_{j}\right) / \omega_{j}, \quad(j=1, \cdots, 4)$ は波数べク トル $\boldsymbol{k}_{j}$ の波の作用(密度), $\phi$ は波数スペクトル， $\omega_{j}$ は角 周波数で， $\omega_{j}^{2}=g k_{j} \tanh k_{j} h$ を満足する．また， $G$ は相互 作用係数（Herterich ら，1980）である.

式（1）は 4 波共鳴の非線形相互作用を表す式で，4 波共鳴条件：

$$
\begin{aligned}
& \boldsymbol{k}_{1}+\boldsymbol{k}_{2}=\boldsymbol{k}_{a}=\boldsymbol{k}_{3}+\boldsymbol{k}_{4} \cdot \\
& \omega_{1}+\omega_{2}=\omega_{a}=\omega_{3}+\omega_{4}
\end{aligned}
$$

を満足する成分波間で非線形相互作用が起こる.

共鳴する 4 つの成分波の波数配置を適切に表現するも のとして Longuet-Higgins (1976)の 4 波相互作用の図が ある (図一1)。図一1 から分かるように， $k_{3}$ と $k_{4}$ が決ま

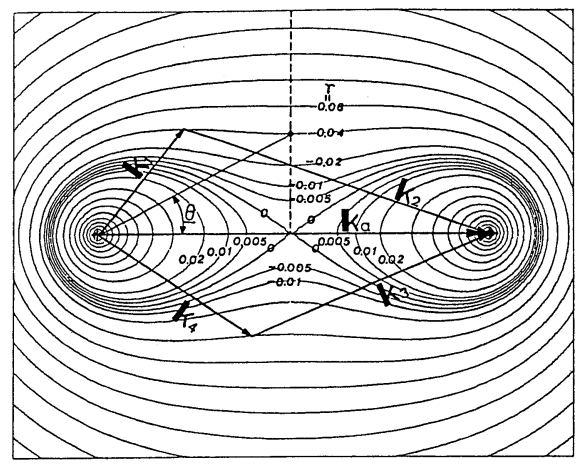

図一1 Longuet-Higgins による共鳴相互作用の図 [Masuda (1980)] 
ると $\boldsymbol{k}_{1}$ と $\boldsymbol{k}_{2}$ は自由度を 1 つ残して決まる。

Longuet-Higgins は $\gamma=\omega_{a} / \sqrt{k_{a}}$ を自由パラメータとし て図一1を作成したが，Masuda（1980）はこの $\gamma を$

$$
\gamma=\sqrt{k_{a}} / \omega_{a}-1 / \sqrt{2} .
$$

と定義し直し, 巧みな方法によって特異点近傍 $(\gamma=0$ 近 傍)の Boltzmann 積分の近似解を導出して, 精度の良い 非線形相互作用の数値計算法を開発した。

以下では Masuda (1980) が定義した $\gamma$ を有限水深の効 果を考慮して,

$$
\gamma=\sqrt{g k_{a} \tanh k_{a} h / 2} / \omega_{a}-1 / \sqrt{2}
$$

と定義し直し, 有限水深域における非線形相互作用の計 算式を導出する.

まず，式（1）で $\boldsymbol{k}_{1} ， \boldsymbol{k}_{2}$ に関する対象性から $\left(\boldsymbol{k}_{1}, \boldsymbol{k}_{2}\right)$ の全空間にわたる積分を $\left|\boldsymbol{k}_{1}\right| \leqq\left|\boldsymbol{k}_{2}\right|$ の半空間にわたる積 分に置き換える。 また, 式 (1) を $\boldsymbol{k}_{2}$ で積分し, $\boldsymbol{k} \rightarrow(\omega$, $\theta$ にに座標変換すると，

$$
\begin{aligned}
& d \boldsymbol{k}=\frac{k}{C_{g}} d \omega d \theta \\
& \phi(\omega, \theta)=\frac{\omega k}{C_{g}} n(\boldsymbol{k})
\end{aligned}
$$

を用いて，式（1）は次式で表される.

$$
\begin{aligned}
& \frac{\partial \phi\left(\omega_{4}, \theta_{4}\right)}{\partial t}=\frac{2 \omega_{4} k_{4}}{C_{g}\left(k_{4}\right)} \iint d \omega_{3} d \theta_{3} \iint d \omega_{1} d \theta_{1} \\
& \times\left\{\frac{k_{1} k_{3} G}{C_{g}\left(k_{1}\right) C_{g}\left(k_{3}\right)}\right\} \delta\left(\omega_{1}+\omega_{2}-\omega_{3}-\omega_{4}\right) \\
& \times\left\{n_{1} n_{2}\left(n_{3}+n_{4}\right)-n_{3} n_{4}\left(n_{1}+n_{2}\right)\right\} \ldots \ldots \ldots \ldots
\end{aligned}
$$

ここで, 式（８）には $k_{1} \leqq k_{2}, \omega_{1} \leqq \omega_{2}, \boldsymbol{k}_{1}+\boldsymbol{k}_{2}-\boldsymbol{k}_{3}-\boldsymbol{k}_{4}=$ 0 の条件が課せられているが，以下では省略する．また， 条件 $k_{1} \leqq k_{2}$ により， $\theta_{1}-\theta_{a}$ をパラメータとすれば $\omega_{1}$ は 一意に決まり， $\gamma<0$ に対して $\theta_{1}-\theta_{a}$ の領域も次のよう に制限される(図一 1 参照).

$$
\Theta=\cos ^{-1}\left(\frac{k_{a}}{2 k_{1}}\right) \leqq\left|\theta_{1}-\theta_{a}\right| \leqq \pi
$$

次に，式（8）を $\omega_{1}$ で積分し，変数変換

$$
\left.\begin{array}{l}
\widetilde{\theta}_{1}=\theta_{1}-\theta_{a}, \widetilde{\theta}_{2}=\theta_{2}-\theta_{a} \\
\widetilde{\theta}_{3}=\theta_{3}-\theta_{4}, \Omega=\ln \omega_{3}
\end{array}\right\}
$$

を施すと，式（8）は最終的に次式で表される.

$$
\begin{aligned}
& \frac{\partial \phi\left(\omega_{4}, \theta_{4}\right)}{\partial t}=\frac{2 \omega_{4} k_{4}}{C_{g}\left(k_{4}\right)} \int_{0}^{\pi} d \widetilde{\theta}_{3} \int_{0}^{\infty} d S \int_{0}^{\pi} d \widetilde{\theta}_{1} \\
& \times \sum_{ \pm} \sum_{ \pm} \sum_{ \pm}\left\{\frac{k_{1} k_{3} \omega_{3}}{C_{g}\left(k_{1}\right) C_{g}\left(k_{3}\right)} \frac{G}{S}\right\} \\
& \times\left\{n_{1} n_{2}\left(n_{3}+n_{4}\right)-n_{3} n_{4}\left(n_{1}+n_{2}\right)\right\}
\end{aligned}
$$



(a) 積分領域



(b) 積分領域の断面図
図一2 積分領域の概略図（a）とその断面図（b） [Masuda (1980)]

$$
\int_{-\pi}^{\pi} d \widetilde{\theta}_{3} \int_{-\infty}^{\infty} d \Omega \int_{-\pi}^{\pi} d \widetilde{\theta}_{1}
$$

は次のように置き換えられている.

$$
\int_{0}^{\pi} d \widetilde{\theta}_{3} \int_{0}^{\infty} d \Omega \int_{0}^{\pi} d \widetilde{\theta}_{1} \times \sum_{ \pm} \sum_{ \pm} \sum_{ \pm}
$$

式（11）の積分領域の概略図を図一2（a）に示す。ただ し, 条件 $k_{1} \leqq k_{2}$ によって, 3 平面 $\widetilde{\theta}_{3}=\pi, \Omega=0, \widetilde{\theta}_{1}=0$ と曲面 $\widetilde{\theta}_{1}=\Theta\left(\widetilde{\theta}_{3}, \Omega\right)$ によって囲まれた左下部の領域は 除外される.

さて, 分母 $S$ は $\delta\left(\omega_{1}+\omega_{2}-\omega_{3}-\omega_{4}\right)$ により生じたもの で，次のように与えられる。

$$
\begin{aligned}
S & =\left|1+\frac{C_{g}\left(k_{2}\right)}{C_{g}\left(k_{1}\right)} \frac{k_{1}-k_{a} \cos \widetilde{\theta}_{1}}{k_{2}}\right| \\
& =\left|1 \pm \frac{C_{g}\left(k_{2}\right)}{C_{g}\left(k_{1}\right)}\left\{1-\frac{k_{a}{ }^{2}}{k_{2}{ }^{2}} \sin ^{2} \widetilde{\theta}_{1}\right\}^{1 / 2}\right| .
\end{aligned}
$$

ただし， $S$ は $\omega_{1}=\omega_{2}$ かつ $\widetilde{\theta}_{1}=0$ のとき $S=0$ になる.す なわち, 式 (11) の被積分関数の特異点は $\widetilde{\theta}_{1}=0$ 上の曲 線 $\gamma=0$ に沿って位置する.したがって,この領域近傍で 積分を実施する際には, 特異点に関する特別な配慮が必 要である.

特異点近傍の積分

式（11）の特異点近傍の積分は, 数值不安定を防ぐた めに Masuda（1980）と同様に以下のように行う.

式 (11)の 3 重積分は $\widetilde{\theta}_{1}, \Omega, \widetilde{\theta}_{3}$ の順に行うので，ま ず $\widetilde{\theta}_{3}=$ 一定の平面において特異点周辺の微小領域 $\mathrm{A}$ を

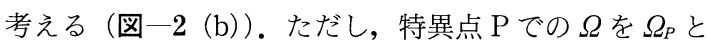
表し, 領域 $\mathrm{A} を \Theta \leqq \widetilde{\theta}_{1} \leqq \delta$ おび $-\varepsilon_{-} \leqq \Omega-\Omega_{P} \leqq \varepsilon_{+}$で 定義する.ここで,

$$
\begin{aligned}
& R=k_{1} k_{3} \omega_{3} G\left\{n_{1} n_{2}\left(n_{3}+n_{4}\right)-n_{3} n_{4}\left(n_{1}+n_{2}\right)\right\} \\
& / C_{g}\left(k_{1}\right) C_{g}\left(k_{3}\right)
\end{aligned}
$$

とし, 特異点での $R$ を $R_{P}$ で表すと, 領域 $\mathrm{A}$ に関する積分 は次式で近似できる。

$$
\iint_{A} d \Omega d \widetilde{\theta}_{1} \frac{R}{S}=R_{P} \iint_{A} d \Omega d \widetilde{\theta}_{1} \frac{1}{S_{P}}
$$

ここで, 


$$
S_{P}=\left[-\frac{2 D_{g}\left(k_{a} / 2\right)}{C_{g}\left(k_{a} / 2\right)}\left\{k_{a} \widetilde{\theta}_{1}^{2}+\frac{2 \sqrt{2} \omega_{a} \mu}{C_{g}\left(k_{a} / 2\right)}\left(\Omega-\Omega_{P}\right)\right\}\right]^{1 / 2}
$$

$$
\begin{aligned}
\mu & =\left(\frac{\partial \gamma}{\partial \Omega}\right)_{P}=\left(\omega_{3} \frac{\partial \gamma}{\partial \omega_{3}}\right)_{\gamma=0} \\
& =\frac{\omega_{3}}{\sqrt{2} \omega_{a}}\left\{\frac{C_{g}\left(k_{a} / 2\right)}{C_{g}\left(k_{3}\right)} \frac{k_{3}+k_{4} \cos \widetilde{\theta}_{3}}{k_{a}}-1\right\}
\end{aligned}
$$

で， $D_{g}(k)=\partial C_{g}(k) / \partial k$ である.なお，式 (17) は式 (14) を特異点近傍の $\tilde{\theta}_{1}$ と $\Omega$ に関する微小量の 2 次オーダー まで展開することにより得られる。

したがって, 式（16）の右辺の積分は最終的には次式 で近似できる。

$$
\begin{aligned}
\iint_{A} d S d \tilde{\theta}_{1} \frac{1}{S_{P}} \\
=\frac{\varepsilon_{+}}{\sqrt{a}} \ln \frac{\mid \sqrt{a} \delta+\sqrt{a \delta^{2}+b \varepsilon_{+} \mid}}{\left|\sqrt{b \varepsilon_{+}}\right|} \\
\quad-\delta \frac{\sqrt{a} \delta-\sqrt{a \delta^{2}+b \varepsilon_{+}}}{b} \\
\quad+\frac{\varepsilon_{-}}{\sqrt{a}} \ln \frac{\mid \sqrt{a} \delta+\sqrt{a \delta^{2}-b \varepsilon_{-} \mid}}{\mid(\sqrt{a c}+\sqrt{a c-b}) \sqrt{\varepsilon_{-} \mid}} \\
\quad+\delta \frac{\sqrt{a} \delta-\sqrt{a \delta^{2}-b \varepsilon_{-}}}{b} \ldots \ldots \ldots . . . . . .
\end{aligned}
$$

ここに,

$$
\begin{aligned}
& a=-\frac{2 k_{a} D_{g}\left(k_{a} / 2\right)}{C_{g}\left(k_{a} / 2\right)}, \quad b=-\frac{4 \sqrt{2} \omega_{a} D_{g}\left(k_{a} / 2\right)}{\left\{C_{g}\left(k_{a} / 2\right)\right\}^{2}} \mu \\
& c=\frac{2 \sqrt{2} \omega_{a}}{k_{a} C_{g}\left(k_{a} / 2\right)} \mu
\end{aligned}
$$

である。

なお, 上の議論は $\mu=0$, すなわち原点 $\widetilde{\theta}_{3}=\Omega=\widetilde{\theta}_{1}=0$ 付近では成立しないが, この原点付近の特異点からの寄 与分は，共鳴 4 波が同一の波数成分を扱う計算法では相 殺されるため計算する必要はない.

以上, 有限水深域を対象として, Masuda (1980)の計 算式を拡張した結果を述べた，本論文で導いた Boltzmann 積分を実施する際に必要な諸量や特異点近傍の近 似解は，水深を無限大にした場合に，Masuda (1980)の 定式化と一致することは, 容易に確かめられる.

\section{3. 非線形相互作用の数値計算法}

2. で導いた計算式を用いて非線形相互作用の計算を 行うため，小松ら（1993）が用いた非線形相互作用の対 称性と 4 波共鳴配置の鏡像性を考慮した計算法を採用し た。詳細は小松らの論文に述べられており，以下では計 算手順の概要を述べることとする.

なお, 小松らの方法は深海波を対象としたものである. この場合には, Boltzmann 積分に含まれる諸量を, 例え ば波数 $\boldsymbol{k}_{4}$ （すなわち $\omega_{4}, \theta_{4}$ ）に着目して，これに相対的
な表現にすると, $G, S, \omega_{1}, \cdots$ 等の諸量は $\widetilde{\theta}_{3}, \widetilde{\Omega}=\ln \left(\omega_{3}\right)$ $\left.\omega_{4}\right), \widetilde{\theta}_{1}$ だけについての関数となる.従って,これらの諸 量は着目する波数 $\boldsymbol{k}_{4}$ (すなわち $\omega_{4}, \theta_{4}$ ） とは無関係にな り, 最初に一回だけ計算すれば, 異なる周波数 $\omega_{4}$ に共通 に使え，計算時間の大幅な節約につながる，しかしなが ら, 有限水深域を対象とする場合には, $G, S, \omega_{1}, \cdots$ 等 の諸量は $\widetilde{\theta}_{3}, \widetilde{\Omega}, \widetilde{\theta}_{1}$ だけでなく, 着目する波数 $\boldsymbol{k}_{4}$ にも 依存する. 従って, 有限水深域を対象とする計算では, $G, S, \omega_{1}, \cdots$ 等の諸量を, 着目する $\omega_{4}$ に関するループ 毎にそれぞれ計算する必要があり, 深海波を対象とした 計算に比べてこの分だけ計算時間を要することになる.

以下の計算では，波数 $\boldsymbol{k}_{4}$ （すなわち $\omega_{4}, \theta_{4}$ ）に着目し て計算することとし，相互作用の対称性より，波 1 ～波 4 の周波数を次のような大小関係に設定して行う.

$$
\omega_{3} \leqq \omega_{1} \leqq \omega_{2} \leqq \omega_{4}
$$

また，連続スペクトルを対象として非線形相互作用の 計算を行うため, $\left(\omega_{4}, \theta_{4}\right)$ に関するループを回して周波 数 $\omega_{4}$ および方向角 $\theta_{4}$ に関する非線形相互作用の計算を 行うが, 周波数 $\omega_{4}$ に関するループを外側のループとし, このループ内で, 下記の特異点付近の核関数の計算と正 則点上の核関数の計算を行い, 方向角 $\theta_{4}$ に関する内側の ループ内で，各周波数・方向角毎に非線形エネルギー伝 達の計算を行うことになる.

特異点付近の核関数の計算

パラメータを $\widetilde{\theta}_{3}$ とする.このとき，鏡像を利用するた めに, $0 \leqq \widetilde{\theta}_{3} \leqq \pi$ とする.この 1 次のループを回して以下 の演算を行う。

1 ) 式 (21) を満足させながら， $\gamma=0$ となるような $\Omega_{P}$ を 求める $\left(\Omega_{P}=\ln \omega_{3}\right)$ ，すなわち， $F_{1}\left(k_{3}\right)=0$ にはさみう ち法を用いた繰り返し計算により $k_{3}$ を求める。ただ し,

$$
\begin{aligned}
& F_{1}\left(k_{3}\right)=\frac{\omega_{a}^{2}}{2}-g k_{a} \tanh \frac{k_{a} h}{2} \\
& \omega_{a}=\sqrt{g k_{3} \tanh k_{3} h}+\sqrt{g k_{4} \tanh k_{4} h} \\
& k_{a}=\sqrt{k_{3}^{2}+k_{4}^{2}+2 k_{3} k_{4} \cos \widetilde{\theta}_{3}}
\end{aligned}
$$

である。

2 ）共鳴条件より $\omega_{1}=\omega_{2}=\omega_{a} / 2$ ，また， $\widetilde{\theta}_{1}=\widetilde{\theta}_{2}=0$ とす る.

3) $\Delta \Omega \equiv \Delta \ln \omega$ として $\widehat{\Omega}_{P}=\left|\Omega_{P} / \Delta \Omega\right|-\left[\left|\Omega_{P} / \Delta \Omega\right|\right]$ を求め $\widehat{\Omega}_{P}<0.5$ なら, 微小領域 A $\Omega \Omega$ についての領域幅を $\varepsilon_{+}=\left(0.5-\widehat{\Omega}_{P}\right) \times \Delta \Omega, \quad \varepsilon_{-}=\left(\widehat{\Omega}_{P}+0.5\right) \times \Delta \Omega$ に設定する.ただし, $\widehat{\Omega}_{P} \geqq 0.5$ なら特異点として扱わな い.

4 ) 式 (19) より核関数

$$
P=k_{1} k_{3} \omega_{3} G /\left\{C_{g}\left\{k_{1}\right) C_{g}\left(k_{3}\right)\right\} \iint_{A} d \Omega d \widetilde{\theta}_{1}\left(1 / S_{P}\right)
$$

を計算する。 
5 ) 波 4 に相対的な波 1 , 波 2 , 波 3 の波数成分の格子点 番号 $\left(I_{j}, J_{j}\right) ; j=1,2,3$ を求め (鏡像も含めて), 核 関数 $P$ とこれら 4 波による可能な配置の対応付けを行 う.な扔, 原点 $\widetilde{\theta}_{3}=\Omega=\widetilde{\theta}_{1}=0$ 付近の特異点からの寄 与分は, 2.に述べた理由により計算する必要はない. 正則点上の核関数の計算

パラメータを $\widetilde{\theta}_{3}, \omega_{3}, \widetilde{\theta}_{1}$ とする.この 3 次のループを 回して以下の演算を行う。ただし，4波共鳴配置の鏡像 性を利用するために， $0 \leqq \widetilde{\theta}_{3} \leqq \pi ， \Theta \leqq \widetilde{\theta}_{1} \leqq \pi$ とする.

$1)$ 式 (21) を満足させながら， $F_{2}\left(k_{1}\right)=0$ にはさみうち 法を用いた繰り返し計算により $\omega_{1}$ および $\omega_{2}, \widetilde{\theta}_{2}$ を求 める.ただし,

$$
\begin{aligned}
& F_{2}\left(k_{1}\right)=\omega_{a}-\sqrt{g k_{1} \tanh k_{1} h}-\sqrt{g k_{2} \tanh k_{2} h} \\
& k_{2}=\sqrt{k_{a}^{2}+k_{1}^{2}-2 k_{a} k_{1} \cos \widetilde{\theta}_{1}} \\
& \widetilde{\theta}_{2}=\tan ^{-1}\left\{\frac{-k_{1} \sin \widetilde{\theta}_{1}}{k_{a}-k_{1} \cos \widetilde{\theta}_{1}}\right\}
\end{aligned}
$$

である。

2 ) 核関数 $K=k_{1} k_{3} \omega_{3} G /\left\{C_{g}\left(k_{1}\right) C_{g}\left(k_{3}\right) S\right\}$ を求める.

3) 波 4 に相対的な波 1 , 波 2 , 波 3 の波数成分の格子点 番号 $\left(I_{j}, J_{j}\right) ; j=1,2,3$ を求め(鏡像も含めて), 核 関数 $K$ とこれら 4 波による可能な配置の対応付けを行 う.

\section{非線形エネルギー伝達の計算}

スペクトルデータ $\phi(I, J)$ を読みとり, 作用 $n=\phi(I$, $J) C_{g} /(\omega k)$ を求める. そして, 波 4 の配列 $\left(I_{4}, J_{4}\right)$ と相対 的な波 1 , 波 2 , 波 3 の配置とにより各周波数・方向毎 に以下の演算を行う.

$1)$ 波 1 , 波 2 , 波 3 の周波数および波向の格子番号 $\left(I_{j}\right.$, $\left.J_{j}\right) ; j=1,2,3$ を

$$
I_{j}=\tilde{I}_{j}+I_{4}, \quad J_{j}=\widetilde{J}+J_{4}
$$

により決める.

2）各波の波数成分に対する作用 $n_{j}=n\left(I_{j}, J_{j}\right) ; j=1,2$, 3,4 を用い, 正則点上の被積分関数

$$
\begin{aligned}
d W_{K}= & 2 \omega_{4} k_{4} K / C_{g}\left(k_{4}\right) \\
& \times\left\{n_{1} n_{2}\left(n_{3}+n_{4}\right)-n_{3} n_{4}\left(n_{1}+n_{2}\right)\right\} \Delta \widetilde{\theta}_{3}
\end{aligned}
$$

および，特異点付近の被積分関数

$$
\begin{aligned}
d W_{P}= & 2 \omega_{4} k_{4} P / C_{g}\left(k_{4}\right) \\
& \times\left\{n_{1} n_{2}\left(n_{3}+n_{4}\right)-n_{3} n_{4}\left(n_{1}+n_{2}\right)\right\} \Delta \widetilde{\theta}_{3} \Delta \Omega \Delta \widetilde{\theta}_{1}
\end{aligned}
$$

を計算し, 作用の変化量 $\Delta n_{j}$ をそれぞれに対応する波 数成分 $\left(I_{j}, J_{j}\right)$ に記憶する.

ここに,

$$
\left\{\begin{array}{l}
\Delta n_{1} \\
\Delta n_{2} \\
\Delta n_{3} \\
\Delta n_{4}
\end{array}\right\}=\left\{\begin{array}{c}
-1 \\
-1 \\
+1 \\
+1
\end{array}\right\} d W
$$

である。

\section{4. 数値計算による検討}

本方法は深水域を対象とした Masuda，小松らの定式 化を含む一般的定式化であり, 深水域を対象とした計算 では, 周波数分割数と方向分割数を $24 \times 36$ と粗く設定し た場合でも, Masuda, 小松らの計算結果と酷似した滑ら かな非線形エネルギー伝達が計算される。しかしながら， 有限水深域, 特に $k_{P} h \sim 1\left(k_{P}\right.$ : 周波数スペクトルのピー ク周波数 $\omega_{P}$ に対応する波数) 付近では, このような粗い 計算格子では非線形エネルギー伝達の計算はやや不安定 で，滑らかさが失われた計算結果となる.

図一3（a)，(b) はそれぞれ周波数スペクトルとして $\omega_{P}=1$ にピークを有する Pierson-Moskowitz (以下 PM) スペクトルおよび JONSWAP スペクトルを対象とし て, 方向関数として方向集中度が周波数によらず一定の $\cos ^{2} \theta$ 型を用い, 周波数分割数と方向分割数を $72 \times 96$ と して, $k_{P} h$ 10, 1.0, 0.8 と変化させた場合の非線形工 ネルギー伝達の計算例を示したものである. 非線形エネ ルギー伝達は式（11）に見られるように, 周波数と方向 角の関数として計算されるが，ここではこれを方向角に 関して積分し, 周波数に関する非線形エネルギー伝達と して示している.

非線形エネルギー伝達の特性は水深と方向スペクトル の形状により異なり, 周波数スペクトルに PM スペクト ルを用いた場合には, 深水域ではピーク周波数 $\omega_{P}$ 付近 で非線形エネルギー伝達は正の極大值を示し， $1.5 \omega_{P}$ 付 近で負の極小值を示す。しかしながら， $k_{P} h \sim 1$ よりも小 さくなると, 非線形エネルギー伝達の正と負の極值はい ずれもやや低周波数側に移動し，絶対值は増大する.

一方, JONSWAP スペクトルの例では, PM スペクト ルの例と異なり, 非線形エネルギー伝達の正の極大值は $0.95 \omega_{P}$ 付近, 負の極小值は $1.1 \omega_{P}$ 付近にあり, $k_{P} h \sim 1$ よ り小さい場合にもそれらの位置はあまり変動せず, 非線 形エネルギー伝達が相似形を保って強化されているよう
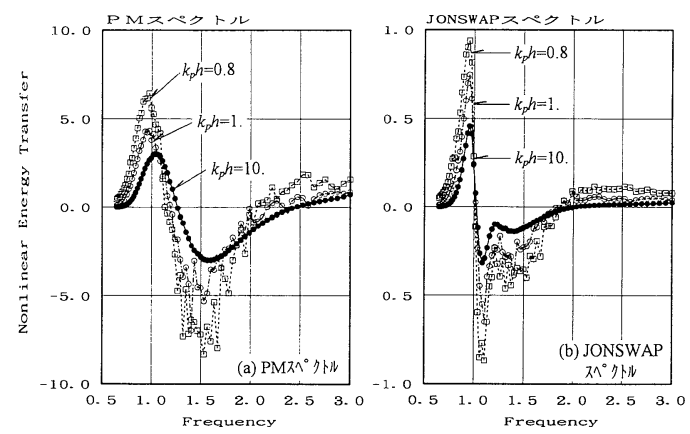

図一3 種々の $k_{P} h$ を対象とした非線形エネルギー伝達の計 算例

（(a）PM スペクトル，(b) JONSWAP スペクトル) 

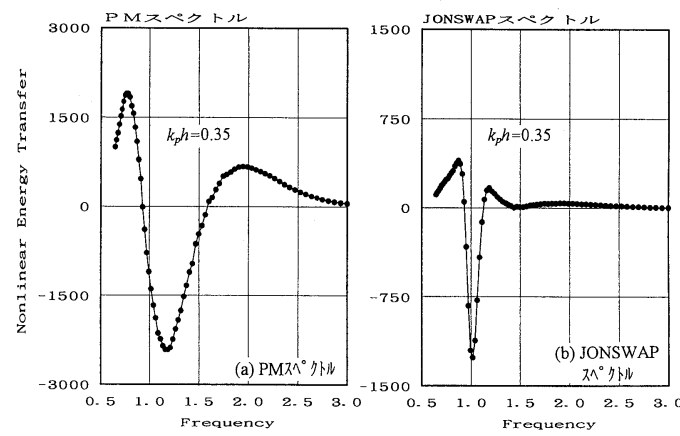

図一 $4 \quad k_{P} h=0.35$ の場合の非線形エネルギー伝達の計算例 （(a) PM スペクトル，(b) JONSWAP スペクトル)



図一5 有限水深域における非線形エネルギー伝達の増幅率

\section{に見える。}

Hasselmann ら (1985) が述べているように，k $k_{P} h \leqq 0.4$ では非線形エネルギー伝達の大きさは深海波の場合に比 べ著しく強化され，非線形相互作用の理論の導出の際に 仮定された弱非線形性の仮定が疑わしくなるが，参考の ため $k_{P} h=0.35$ の計算例を示したものが図一 4 (a)，(b) である. 图-3 の例に比べて絶対值が著しく増大し, 非線 形エネルギー伝達の特性も方向スペクトル形状に依存し てかなり異なることが分かる。

図一5 は種々の $k_{P} h$ を対象として非線形エネルギー伝 達を計算し,

$$
R\left(k_{P} h\right)=S_{\mathrm{nl}}\left(k_{P} h\right)_{\text {peak }} / S_{\mathrm{nl}}(\infty)_{\text {peak }}
$$

によって，有限水深域における非線形エネルギー伝達の 增幅率を計算したものである。ここに, $S_{\mathrm{n}}\left(k_{P} h\right)_{\text {peak }}$ は $k_{P} h$ をパラメータとして計算した非線形エネルギー伝達の正 の極大值である．図一 5 中の○と○はそれぞれ周波数ス ペクトルにPM スペクトルと JONSWAP スペクトルを 用いた場合の計算例である。また，図中の破線と実線は， 参考のために Hasselmann ら（1985）の論文から引用し
た非線形エネルギー伝達の増幅率である。ただし，Hasselmann らの計算は方向関数に Mitsuyasu-Hasselmann 型を用いており，著者らの計算条件とは異なるが，両者 は概してよく一致している. Hasselmann らを中心とし て開発された第三世代波浪推算モデル (WAMDI Group, 1988)では, 有限水深域における波浪推算では図一5 亿示 した非線形エネルギー伝達の増幅率を深海波の非線形エ ネルギー伝達に乗じることとで対処している，図一5では 周波数スペクトルの相違による非線形エネルギー伝達の 増幅率に大差は見られないが, 実際には図 -3 や图 -4 に 見られるように非線形エネルギー伝達の形状や極值の位 置はかなり異なるので注意が必要である.

なお，種々の $k_{P} h$ を対象とした筆者らの非線形エネル ギー伝達の計算結果と, Hasselmann ら (1981)の厳密計 算結果を比べると, 筆者らの非線形エネルギー伝達の計 算結果に見られる変動は Hasselmann らの厳密計算結 果と同程度あるいはそれ以下であった。

\section{5. あとがき}

Masuda（1980)，小松ら（1993）の理論を拡張し，深 水域のみならず有限水深域にも適用可能な非線形相互作 用に関する計算式の定式化を行った。今後, 本方法をも とに種々の方向スペクトルを対象として有限水深域にお ける非線形相互作用の検討を進める予定である。本研究 を実施するに際しては, 九州大学応用力学研究所の増田 章教授および小松幸生博士には種々適切な御助言, 御指 導を頂いた。ここに記して深甚の謝意を表します。

\section{参 考 文 献}

Hasselmann, K. (1962): On the non-linear energy transfer in a gravity-wave spectrum, Part 1, General theory, J. Fluid Mech., 12, pp. 481-500.

Hasselmann, S. and K. Hasselmann (1981): A symmetrical method of computing the nonlinear transfer in a gravity wave spectrum, Hamb. Geophys. Einzelschriften, Reihe A : Wiss. Abhasand., 52, 138 p.

Hasselmann, S. and K. Hasselmann (1985): Computations and Parameterizations of the Nonlinear Energy Transfer in a Gravity-Wave Spectrum. Part I: A New Method for Efficient Computations of the Exact Nonlinear Transfer Integral, J. Phys. Oceanogr., 15, pp. 1378-1391.

Herterich, K. and K. Hasselmann (1980)： A similarity relation for the nonlinear energy transfer in a finite-depth gravitywave spectrum, J. Fluid Mech., 97, pp. 215-224.

Masuda, A. (1980): Nonlinear Energy Transfer Between Wind Waves, J. Phys. Oceanogr., 10, pp. 2082-2092.

The WAMDI Group (13 Authors) (1988): The WAM modelA third generation ocean wave prediction model, J. Phys. Oceanogr., 18, pp. 1378-1391.

小松幸生・草場忠夫・増田 章（1993）：風波成分波間の非線形 エネルギー伝達一新しく開発した効率的な計算法につい て一, 九州大学応用力学研究所報, 第 75 号, pp. 121-146. 